\title{
ANNOTATION
}

\section{Standards of Visual Acuity in Industry}

The question of eye sight in industry is one to which increasing attention has been devoted of late years. No one can dispute the proposition that, other things being equal, the employee with perfect sight will be in a better position for doing work than one handicapped by visual defects. But, to insist on a $6 / 6$ standard would be Utopian, and were such a standard rigidly enforced grave injustice would be done to many perfectly competent workpeople. The Royal Navy has for many years demanded a high standard of vision and rightly so; but it is to be noted that it is only 143 years since Nelson's eye became blind. This did not invalidate him or prevent him from winning most of his famous sea battles.

An agricultural labourer who has to pleach a hedge, clean out ditches or scythe a meadow obviously does not need so high a standard of vision as the driver of an express train or one who has to work on scaffolding, yet all are engaged in industry.

It seems to us that what is needed in this question of eye sight in industry is to try and establish minimum standards for the various branches of industry. Such standards, recorded by Snellen's test types, would need to be on a sliding scale and some latitude would be permissible in the various trades. Mrs. Gamp once laid down the law that use is second nature; and in our opinion there are probably many cases where long experience in any particular work may well outweigh some degree of visual defect.

A case in point is that of a gardener of our acquaintance. His visual acuity is very bad owing to tobacco amblyopia and his dislike to giving up tobacco. Yet he can see to clip a hedge quite well and he is first-class at digging a bed and maintaining a level. His greatest trouble is to decide between what are weeds and what are young plants.

Let us consider for a moment the standard of vision demanded by the regulations for motorists in this country. Judged by Snellen's types this works out at between $6 / 18$ and $6 / 12$, with or without glasses. Let us call it $6 / 12$.

If a medium standard of this sort is deemed sufficient for fast moving traffic on the roads, what should be the standard on the railways where traffic is running on lines confined to a track and where little else should be moving?

Express drivers obviously need a high visual acuity. If we were asked to set a standard for such men we would suggest a minimum standard of $6 / 9$ binocularly, allowing one eye to be $6 / 12$. The 
drivers of fast goods trains should we think conform to the same standard, but those of the slower goods trains might well be passed on a minimum of $6 / 12$ binocular standard. Coming to men who work on the line it seems to us that the standard might well be much lower and we would suggest a binocular standard of $6 / 24$ or better for plate-layers. The eyes must be healthy apart from errors of refraction and the fields must show no gross defects. And here we meet the difficulty that with increasing years the sight of hypermetropes diminishes. A lad of 16 years of age with 3 or 4 dioptres of hypermetropia will easily pass the $6 / 6$ standard as a rule. When he gets to the age of 50 years his unaided vision will be nothing like so good. But by this age he will probably have spent close on 30 years at his job and presumably knows it thoroughly. It would be very hard lines were he to be dismissed from his post simply on account of failure of accommodation.

So far as we are aware the railway companies do not allow their employees to wear glasses at work. This restriction is quite correct in the case of drivers, where the lenses might easily become clouded by rain, steam from heat in the cab, and other causes. But for most other types of railway men we see no reason why glasses of the non-splintering type should not be allowed; and we think that the authorities might reasonably relax their regulations in this respect.

In connexion with the point made about scaffolders we remember a middle-aged man who got a detachment of the retina in one eye. The other eye was moderately myopic, with corrected vision of $6 / 9$ part. The vitreous was full of opacities and very fluid and we looked upon him as very likely to get a detachment in the other eye at some later date. We advised that he should be taken off scaffolding work and found employment on the ground. A couple of years or so later we heard that he was still at work as a scaffolder.

Doubtless it would be a formidable task for any committee to define minimum standards of visual acuity that would co er all branches of industry, but we cannot help feeling that the appointment of such a committee would be a good move. And we believe that many employers of labour would be willing to appoint representatives to give evidence on special points which might arise. Of course it would not be easy to overcome the age-long distaste of the average workman for wearing glasses at his work; but time would almost certainly tell in the long run in such cases. 